\title{
Asymptomatic nutcracker phenomenon: entrapment of the left renal vein shown by CT without left flank or pelvic pain, or macroscopic haematuria
}

\author{
Masaki Tago (ㄷ), Naoko E Katsuki, Yuka Hirakawa, Shu-ichi Yamashita
}

General Medicine, Saga University Hospital, Saga, Japan

\section{Correspondence to} Dr Masaki Tago; tagomas@cc.saga-u.ac.jp

Accepted 18 December 2019

\section{DESCRIPTION}

A 65-year-old woman presented with a 6-month history of mild epigastric pain without weight loss, left flank pain, pelvic pain, or macroscopic haematuria. Previously, during a routine medical check-up, she had been shown to have liver dysfunction. Subsequent abdominal ultrasonography incidentally revealed dilatation of the left renal vein. At the present evaluation, urinalysis showed no microscopic haematuria. Corticomedullary phase images of abdominal contrast-enhanced CT (CECT) revealed dilatation of the left renal vein in the upper stream of the region compressed between the superior mesenteric artery (SMA) and the aorta (figures 1 and 2). They also showed a dilated left lumbar vein with possible collateral circulation (figure 3), suggesting a diagnosis of the asymptomatic nutcracker phenomenon (NCP).

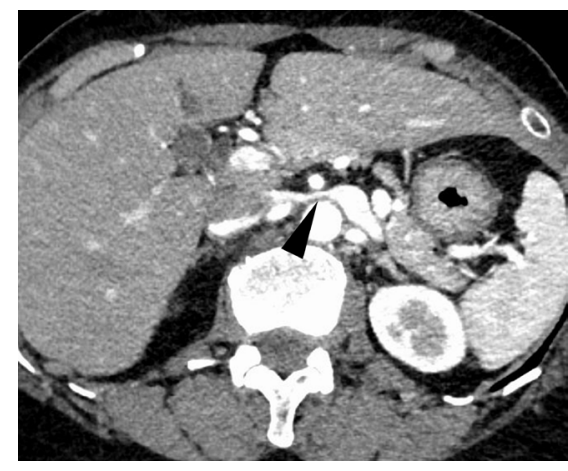

Figure 1 Corticomedullary-phase, axial, contrastenhanced CT image shows the beak sign and a dilated left renal vein that is compressed between the superior mesenteric artery and the aorta (arrowhead).

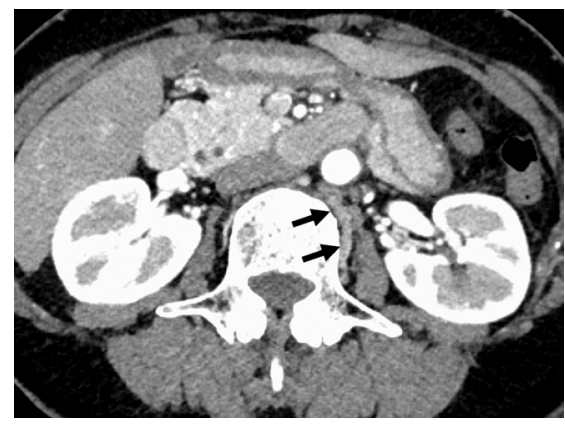

Figure 3 Corticomedullary-phase, axial, contrastenhanced CT image shows that the left lumbar vein is dilated to $4.2 \mathrm{~mm}$ diameter with signs of reflux (arrows).
NCP is defined by its imaging findings, that is, entrapment of the left renal vein between the SMA and the aorta, regardless of the presence of symptoms. ${ }^{12}$ Among its presentations, symptomatic NCP, identified by such symptoms as haematuria or left flank or pelvic pain, has been designated the nutcracker syndrome (NCS). Its clinical features are thought to be caused by dilatation of the renal veins or formation of varices in the testicular or ovarian veins that flow into renal veins due to obstruction

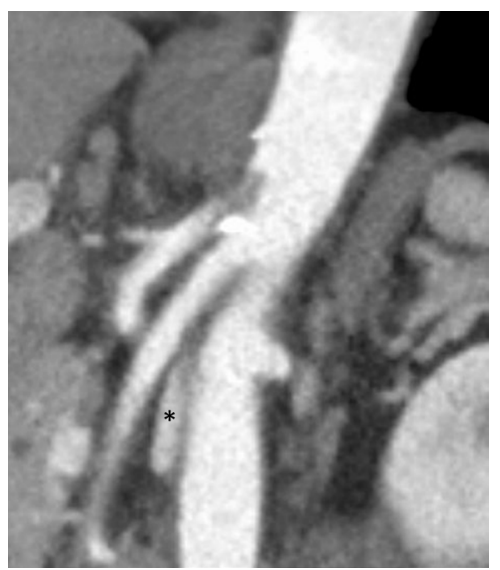

Figure 2 The reconstruction contrast-enhanced CT image reveals that the left renal vein is entrapped between the superior mesenteric artery and the aorta (asterisk).

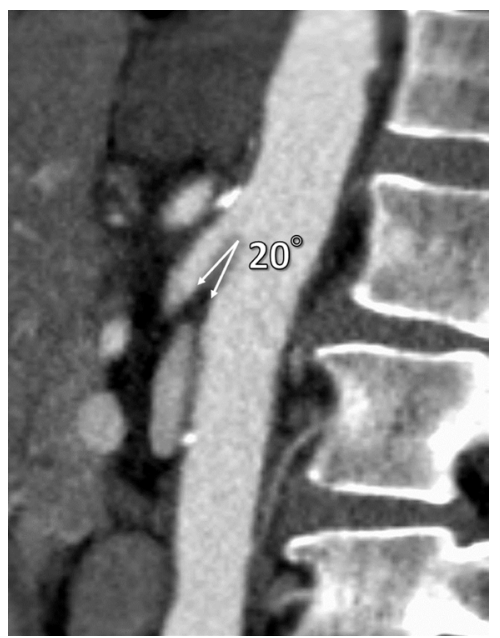

Figure 4 The sagittal reconstruction contrast-enhanced $\mathrm{CT}$ image shows an superior mesenteric artery-aortic angle of $20^{\circ}$ (arrows). 


\section{Learning points}

Asymptomatic nutcracker phenomenon may be diagnosed despite CT images typical of the nutcracker syndrome (NCS). Careful follow-up and observation of such patients are essential for applying timely treatment for possible emerging symptoms.

- The (1) beak sign, (2) a hilar-to-aortomesenteric diameters ratio of $\geq 4.9$ or (3) the combination of a superior mesenteric artery-aortic angle $<25^{\circ}$ and visualisation of a dilated collateral vein with signs of reflux were reported to be useful $\mathrm{CT}$ imaging clues for diagnosing NCS.

of their normal venous return. ${ }^{3}$ In contrast, NCP without any symptoms, despite displaying typical imaging findings, is called the asymptomatic NCP. ${ }^{3}$

Useful CE-CT clues for diagnosing NCP include (1) the beak sign, (2) a hilar diameter-to-aortomesenteric diameter ratio of $\geq 4.9$, or (3) a combination of the SMA-aortic angle of $<25^{\circ}$ and visualisation of a dilated collateral vein with signs of reflux. The sensitivity and specificity of these three diagnostic clues are $91.7 \%$ and $88.9 \% ; 66.7 \%$ and $100 \% ; 80.0 \%$ and $88.2 \%$, respectively. $^{3-5}$ Our patient exhibited the beak sign (figure 1) and the combination of an SMA-aortic angle $<25^{\circ}$ (figure 4) and visualisation of a dilated collateral vein with signs of reflux (figure 3). The large diameter ratio was not present.

Epigastric pain is not a typical symptom of NCS, although a patient with NCP and epigastric pain due to a complicated SMA syndrome has been reported. ${ }^{6}$ CE-CT revealed no findings of SMA syndrome in the present patient.

Contributors MT: involved in literature search, study conception and manuscript drafting. NEK: involved in study conception and manuscript drafting. YH: involved in manuscript drafting and clinical care of the patient. S-iY: involved in study conception and manuscript revision.

Funding The authors have not declared a specific grant for this research from any funding agency in the public, commercial or not-for-profit sectors.

Competing interests None declared.

Patient consent for publication Obtained.

Provenance and peer review Not commissioned; externally peer reviewed.

ORCID iD

Masaki Tago http://orcid.org/0000-0003-1092-1834

\section{REFERENCES}

1 Kurklinsky AK, Rooke TW. Nutcracker phenomenon and Nutcracker syndrome. Mayo Clin Proc 2010;85:552-9.

2 Butros SR, Liu R, Oliveira GR, et al. Venous compression syndromes: clinical features, imaging findings and management. Br J Radiol 2013;86:20130284.

3 Ananthan K, Onida S, Davies AH. Nutcracker syndrome: an update on current diagnostic criteria and management guidelines. Eur J Vasc Endovasc Surg 2017;53:886-94.

4 Kim KW, Cho JY, Kim SH, et al. Diagnostic value of computed tomographic findings of Nutcracker syndrome: correlation with renal venography and renocaval pressure gradients. Eur J Radiol 2011;80:648-54.

5 Yun SJ, Lee JM, Nam DH, et al. Discriminating renal Nutcracker syndrome from asymptomatic Nutcracker phenomenon using multidetector computed tomography. Abdom Radiol 2016;41:1580-8.

6 Vulliamy P, Hariharan V, Gutmann J, et al. Superior mesenteric artery syndrome and the 'nutcracker phenomenon'. BMJ Case Rep 2013;2013:bcr2013008734.

Copyright 2020 BMJ Publishing Group. All rights reserved. For permission to reuse any of this content visit

https://www.bmj.com/company/products-services/rights-and-licensing/permissions/

BMJ Case Report Fellows may re-use this article for personal use and teaching without any further permission.

Become a Fellow of BMJ Case Reports today and you can:

- Submit as many cases as you like

- Enjoy fast sympathetic peer review and rapid publication of accepted articles

- Access all the published articles

- Re-use any of the published material for personal use and teaching without further permission

Customer Service

If you have any further queries about your subscription, please contact our customer services team on +44 (0) 2071111105 or via email at support@bmj.com.

Visit casereports.bmj.com for more articles like this and to become a Fellow 